\title{
Algılanan Akademik Yeterlik ve Özerklik Desteğinin Özerk Akademik Motivasyon ve Akademik Başarıyla İlişkisisi ${ }^{1}$ \\ The Relationship Between Perceived Autonomy Support and Academic Competence with Autonomous Academic Motivation and Academic Success
}

\author{
Şükran CALP ${ }^{2} \quad$ Hasan BACANLI ${ }^{3}$
}

\begin{abstract}
Başvuru Tarihi: 23.06.2016
Özet: $\mathrm{Bu}$ çalışma, yeterlik algısı, özerklik ve özerklik desteği gibi öz belirleme kuramı kaynaklı çeşitli değişkenlerin özerk akademik motivasyon ve akademik başarıya etkisine odaklanmıştır. Çalışmada ilköğretim beşinci sınıf öğrencilerinin algıladığı öğretmen ve yakın arkadaş özerklik desteğinin, akademik yeterlik, akademik özerklik ve özerk akademik motivasyona, özerk akademik motivasyonun da akademik başarıya etkisi araştırılmıştır. Araştırmanın genel amacı, akademik başarıyla ilgili, öz belirleme kuramı temelli bir motivasyonel modeli test etmektir. Araştırma, tarama modelinde betimsel bir çalışma olup araştırmaya 849 ilköğretim beşinci sınıf öğrencisi katılmıştır. Araştırma kapsamında test edilen modeldeki değişkenleri ölçmek için beş farklı ölçek kullanılmıştır. Ölçek maddelerine verilen tepkiler, yapısal eşitlik modeliyle (YEM) analiz edilmiştir. Sonuçlar, ilköğretim beşinci sınıf öğrencilerinin okulla ilgili konularda öğretmenlerinden aldı ̆̆ 1 özerklik desteğinin akademik yeterlik algısını doğrudan etkilediğini; ancak arkadaşlardan alınan özerklik desteğinin akademik yeterliliği etkilemediğini göstermektedir. Öğrencilerin okulla ilgili konularda öğretmenlerinden aldığı özerklik desteği onların akademik özerkliklerini doğrudan etkilemektedir. Okulla ilgili konularda yakın arkadaşlardan alınan özerklik desteği, öğrencilerin akademik özerkliklerini doğrudan fakat zayıf düzeyde etkilemektedir. Öğrencilerin özerk (öz belirlenmiş) akademik motivasyonları, onların okul performansını doğrudan etkilemektedir. RMSEA, RMR AGFI, GFI, NFI gibi uyum indeksleri incelendiğinde modelin kabul edilebilir uyum düzeyinde olduğunu söylemek mümkündür.
\end{abstract}

Anahtar Kelimeler: $\ddot{O} z$ belirleme, özerklik, özerklik desteği, yeterlik, özerk akademik motivasyon, akademik başarı.

\begin{abstract}
This study focused on the impact of various variables based on self determination theory such as the "perceived competence", "autonomy" and "autonomy support" to autonomous academic motivation and academic achievement. In this study the effect of teachers and close friends's autonomy support perceived by primary fifth grade students' to academic competence, academic autonomy and autonomous academic motivation, and the effect of autonomous academic motivation to academic success are researched. The main aim of the study is to test the self-determination theorybased motivational model on academic success. The study group consists of 849 fifth grade students. Five different scales used to measure the variables in the tested model within the scope of research. Responses to scale items used in order to collect quantitative data were analyzed by structural equation modeling (SEM). The results of the quantitative measurements that fifth grade students' autonomy support get by teachers directly influence the perceived competence, but the results of the quantitative measurements that autonomy support get by close friends didn't influence academic competence. Students' autonomy support get by close friends on the issues related school directly influence their academic autonomy but this effect is low. Finally, students' autonomous (selfdetermined) academic motivations influences directly their school performance (academic achievement). According to RMSEA, AGFI, RMR, GFI, NFI fit indices it is likely to say that the model is acceptable.
\end{abstract}

Keywords:Self determination, autonomy, autonomy support, competence, autonomous academic motivation, academic achievement.

\section{Giriş}

Merak, insanoğlu için temel bir eğilimdir. Keşfetme, öğrenme, anlama veya bilme arzusu, insanın doğasında vardır ve potansiyel olarak eğitim sürecinin ana motive edicisidir. Grolnick, Deci ve Ryan'a

\footnotetext{
${ }^{1} \mathrm{Bu}$ çalışma, Şükran Calp'in Prof. Dr. Hasan BACANLI danışmanlığında yürüttüğü “Algılanan Akademik Yeterlik ve Algılanan Özerklik Desteğinin Özerk Akademik Motivasyon ve Akademik Başarıyla İlişkisi”” adlı doktora tezinden üretilmiştir.

${ }^{2}$ Yrd. Doç. Dr., Erzincan Üniversitesi, Erzincan Eğitim Fakültesi, demetsukran_calp@ @otmail.com

${ }^{3}$ Prof. Dr., Üsküdar Üniversitesi, İnsan ve Toplum Bilimleri Fakültesi, hasan.bacanli@gmail.com
} 
göre (1997), bireyin sosyal etkileşim sürecinde karşılaştığı ve gözlemlediği değer, tutum ya da davranışları benimsemesi ve içselleştirmesi, motivasyon mekanizmaları aracılığıyla gerçekleşmektedir.

Eğitim literatüründe motivasyon ve motivasyonun çeşitli değişkenlerle ilişkisini inceleyen birçok çalışma bulunmaktadır. Böyle çalışmalar, özerk akademik motivasyonun, üst düzey yaratıcılığı; daha az okulu bırakma davranışını; öğrencinin okula psikolojik yatırımı ya da karışık ve zor konulara karşı gerekli enerjiyi harcamada istekli ve özenli oluşu anlamındaki bilişsel bağlılı̆g 1 ve daha iyi bir kavramsal öğrenmeyi beraberinde getirdiğini açığa çıkarmıştır (Amabile, 1982; Vallerand ve Bissonnette, 1992; Vallerand, Fortier ve Guay, 1997; Nolen ve Haladyna, 1990; Pintrich ve De Groot, 1990; Graham ve Golan, 1991; Grolnick ve Ryan, 1987).

Üzerinde uzun zamandır bir hayli inceleme yapılan diğer bir eğitimsel çıktı da akademik performans ya da diğer bir ifadeyle akademik başarıdır. Akademik başarıya atfedilen bu değer, onun çeşitli yönleriyle araştırılmasını gerekli kılmaktadır. Akademik performans ve motivasyon çalışmaları için geçerli ve gelecek vaadeden bir yaklaşım, Deci ve Ryan'ın (1980) "öz belirleme teorisi (self determination theory)" adı altında şekillendirdikleri motivasyonel yaklaşımdır. Bu teorik yaklaşım, son zamanlarda eğitim alanındaki araştırmaların önemli bir miktarını oluşturmuş ve öğrenme, okula uyum, okul performansı ya da okulu bırakma davranışı gibi birçok önemli eğitimsel çıktıyı daha iyi anlayabilmek için kullanılmıştır.

Deci ve Ryan'ın (1985) motivasyon yaklaşımı, farklı motivasyon tipleri ve onların psikolojik sonuçlarını (öğrenme, performans vb.) değerlendirdiği için eğitim literatüründe önemli bir yere sahip olmuştur. Öz belirleme teorisine göre, davranışın düzenlenmesinde üç genel kategori vardır: iç/içsel motivasyon, dış/dışsal motivasyon ve amotivasyon; yani herhangi bir durumdaki insan davranışları içsel olarak motive olabilir, dışsal olarak motive olabilir ya da amotive olabilir.

İçsel motivasyon bir aktiviteye doyum ve hoşnutluk için bağlanmaya vurgu yapar. İçsel motivasyonun aksine dişsal motivasyon, kendine özgü doğal sebeplerden değil, bir araca bağlı olan sebeplerden dolayı bir aktiviteye bağlanmayı vurgular. İçsel ve dışsal motivasyon arasındaki temel farklılık, davranış nedenselliğinin odağıyla ilgilidir. İçsel motivasyonda kontrol bireyin kendinde, dışsal motivasyonda ise çevrededir (Deci ve Ryan, 2012).

Gerek motivasyonun gerekse öz belirleme halinin hiç olmadığı "amotivasyon" ise, bir bakıma “öğrenilmiş çaresizlik”tir. Güdü yoksunluğu veya eksikliği, olumsuz duyguları beraberinde getirir ve öğrenilmiş çaresizliğin kapısını aralar. Amotivasyon durumunu yaşayan bireyler kendilerinde var olan potansiyel güçlerin ya farkında değillerdir ya da var olan gizil güçlerini kullanamazlar. Bu hal öğrenmede çok önemli bir yere sahip olan bir etkinliğe duyulan ilgi, katılım, ön bilgileri harekete geçirme, yaratıcılık ve akademik başarı gibi değişkenler üzerinde olumsuz bir etkiye yol açar.

Öz belirleme kuramına göre insan davranışında üç motivasyonel etken vardır: Yeterlik, özerklik ve ilişkili olma. Kuram, bu üç motivasyonel belirleyicinin evrensel olduğunu ileri sürmektedir (Deci ve Ryan, 1985; Kowal ve Fortier, 1999; Ryan ve Deci, 2000, Véronneau, Koestner ve Abela, 2005). Farklı kültürel ortamlarda yaşıyor olsalar bile, sağlıklı bir gelişim gösterebilmeleri için tüm insanların bu temel psikolojik ihtiyaçları doyurması gerekmektedir. Bu ihtiyaçların giderilmesi durumunda bireyler davranışlarını daha çok içsel sebeplere dayandırabilir, bu yolla sosyal ve psikolojik doyuma ulaşabilirler. Sonuç olarak bu doyum halinin, öğrenme ortamını doğrudan ve olumlu bir şekilde etkileyeceği düşünülmektedir.

Kuramda adı geçen "öz belirleme" ifadesi, özerkliğe atıfta bulunur. Özerklik, bireyin kendisini eylemlerinin merkezinde hissetmesidir (Kowal ve Fortier, 1999). Özerklik duygusunun bireysel performans ve olumlu tutum geliştirme üzerinde güçlü bir etkisi vardır. Son yıllarda yapılan birçok araştırma sonucuna göre, özerk motivasyon, öğrencilerin kavramsal anlama düzeyini ve notlarını dolayısıyla akademik başarısını yükseltmekte, çalışma azimlerini artırmaktadır (Guay, Boggiano ve 
Vallerand, 2001; Wong, Wiest ve Cusick, 2002; Wößmann, Schütz, Lüdemann ve West 2007; Wößmann, 2007; Deci ve Ryan, 2008; Lowe, 2009).

Özerklik hissi için en önemli kaynaklardan biri aile, öğretmen, arkadaş gibi sosyal çevre elemanlarının özerkliği destekleyici tutumlarıdır. Bireyin özerklik hissedebilmesi ve özerk davranabilmesi, çevrenin özerklik desteğiyle yakından ilişkilidir. Sadece özerklik değil, öz belirleme kapsamında ele alınan diğer iki psikolojik ihtiyaç olan yeterlik ve ilişkili olma için de sosyal çevrenin katkısı büyüktür.

Kuramda bahsedilen psikolojik ihtiyaçlardan bir diğeri yeterlik, Kowal ve Fortier'e göre (1999) bireyin çevresiyle yeterli ya da etkili olarak iletişimde olma isteğidir. Benzer şekilde Deci ve Ryan da (1985) yeterliliği, çevreyle etkili bir biçimde etkileşimde bulunma ve çevreye uyum sağlama kapasitesi olarak tanımlamaktadır. Bireyin kendisiyle ilgili olarak hissettiği yeterlik duygusu, onun davranışlarını, kararlarını, çaba düzeyini, öğrenmesini ve sonuç olarak başarısını etkilemektedir (Ormrod, 1999; Cihangir-Çankaya, 2005). Buradan yeterliliğin, özerkliğin alt boyutlarından biri olduğu ya da özerkliğin yeterliği içerdiği sonucuna ulaşılabilir.

İlişkili olma ise, bireyin başkaları ile bağlantılı olma ve içinde bulunduğu sosyal çevreyle ilgili aidiyet hissini yaşama isteğidir (Kowal ve Fortier, 1999). İlişkili olma ihtiyacı karşılıklı saygıyı, samimiyeti, duyarlılığı, özeni, başkalarına güvenmeyi gerektirmektedir (Andersen, 2000). Kuramda adı geçen özerklik, yeterlik ve ilişkili olma ihtiyacının engellenmesi ya da kişinin bu ihtiyaçları tatmin edememesi, Deci ve Ryan'a göre (2000) içsel motivasyon ve iyi olmada azalmaya ve performans düşüklüğüne neden olmaktadır.

Bu çalışma, özerklik desteği, yeterlik algısı ve özerklik gibi öz belirleme kuramı kaynaklı çeşitli değişkenlerin özerk akademik motivasyon ve akademik başarıya etkisine odaklanmıştır. İyi olma, yaşam doyumu, üst düzey yaratıcılık gibi çeşitli değişkenler üzerinde olumlu etkisi olduğu düşünülen öz belirleme kuramı ilkelerinin, akademik başarı üzerinde nasıl bir etkisinin olduğunu ortaya çıkarmak bu araştırmanın problemidir. Çalışmanın sonuçlarının sınıf öğretmenleri, okul yöneticileri ve ailelere öğrencilerin özerk akademik motivasyonları ve akademik başarılarını artırmak için önemli kaynak sağlayacağı, ayrıca akademislerde de özerk motivasyon, özerklik, çevre özerklik desteği, yeterlik gibi konularda farkındalık oluşturacağı düşünülmektedir.

Çalışmanın Amacı ve Hipotezleri

$\mathrm{Bu}$ çalışmada ilköğretim 5. sınıf öğrencilerinin algıladığı öğretmen ve yakın arkadaş özerklik desteğinin, akademik yeterlik, akademik özerklik ve özerk akademik motivasyona, özerk akademik motivasyonun da akademik başarıya etkisi araştırılmıştır. Araştırmanın genel amacı, akademik başarıyla ilgili, öz belirleme kuramı temelli bir motivasyonel modeli test etmektir.

Çalışmanın genel amacı doğrultusunda aşağıdaki hipotezler test edilmiştir:

1. İlköğretim 5. Sınıf öğrencilerinin okulla ilgili konularda öğretmenlerinden aldığı özerklik desteği onların akademik yeterliklerini doğrudan etkilemektedir.

2. İlköğretim 5. Sınıf öğrencilerinin okulla ilgili konularda yakın arkadaşlarından aldığı özerklik desteği onların akademik yeterliklerini doğrudan etkilemektedir.

3. İlköğretim 5. Sınıf öğrencilerinin okulla ilgili konularda öğretmenlerinden aldığı özerklik desteği onların akademik özerkliklerini doğrudan etkilemektedir.

4. İlköğretim 5. Sınıf öğrencilerinin okulla ilgili konularda yakın arkadaşlarından aldığı özerklik desteği onların akademik özerkliklerini doğrudan etkilemektedir.

5. İlköğretim 5. Sınıf öğrencilerinin okulla ilgili konularda öğretmenlerinden aldığ özerklik desteği onların özerk akademik motivasyonların etkilemektedir. 
6. İlköğretim 5. Sınıf öğrencilerinin okulla ilgili konularda yakın arkadaşlarından aldığı özerklik desteği onların özerk akademik motivasyonlarını etkilemektedir.

7. İlköğretim 5. Sınıf öğrencilerinin kendileriyle ilgili algıladıkları akademik yeterlik, özerk (öz belirlenmiş) akademik motivasyonlarını doğrudan etkilemektedir.

8. İlköğretim 5. Sınıf öğrencilerinin kendileriyle ilgili algıladıkları akademik özerklik, onların özerk (öz belirlenmiş) akademik motivasyonlarını doğrudan etkilemektedir.

9. İlköğretim 5. Sınıf öğrencilerinin özerk (öz belirlenmiş) akademik motivasyonları, onların okul performansını (akademik başarı) doğrudan etkilemektedir.

10. Elde edilen veriler modelle uyum göstermektedir.

\section{Yöntem}

Araştırmanın Modeli

Araştırma, yapısal eşitlik modelinin kullanıldığı betimsel bir çalışmadır. Araştırmada hali hazırda var olan durum var olduğu şekliyle betimlemek amaçlanmış nedensel-karşılaştırmalı araştırma modeli kullanılmıştır. Öz belirleme teorisi temelli özerk akademik motivasyon ve akademik başarıya ilişkin çok değişkenli bir model önerilmiş, bu modelin test edilmesi için path analizi yapılmıştır. Path analizi, yapısal eşitlik modellerinde gözlenen ve gizil değişkenler arasındaki nedensel ilişkileri sınamada kullanılan kapsamlı bir istatistiksel yaklaşımdır.

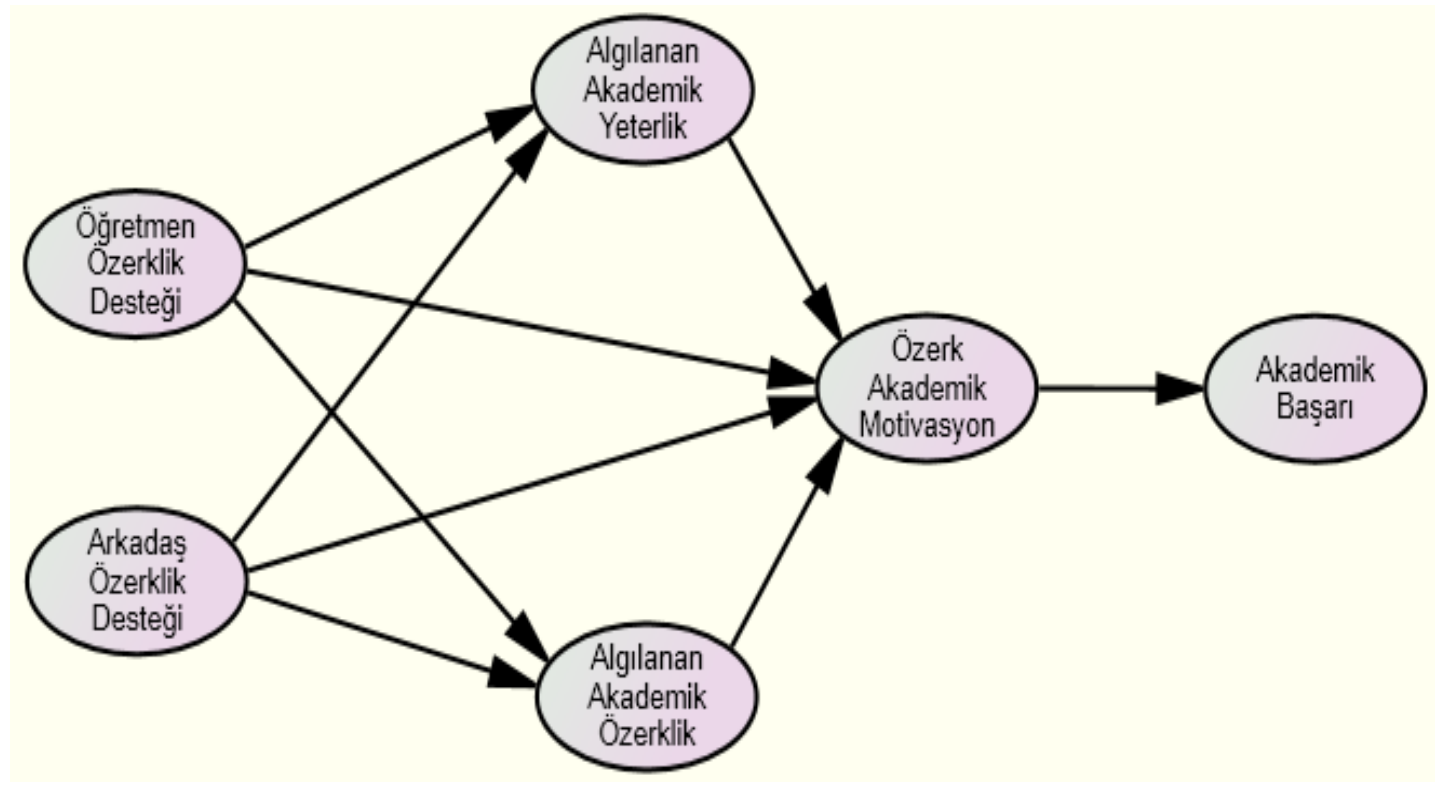

Şekil 1.

Okul başarısının motivasyonel modeli

Çalışma kapsamında şekil l'de görülen okul başarısının motivasyonel modeli test edilecektir. Model temelde üç savı ileri sürmektedir. İlki, gerek yakın arkadaşlar gerekse sınıf öğretmenlerinden alınan özerklik desteği, öğrencilerin akademik yeterlik ve akademik özerklik hissini doğrudan ve olumlu yönde etkilemektedir. İkincisi öğrenciler tarafından algılanan yeterlik ve özerklik hissi, onların özerk akademik motivasyonlarını doğrudan ve olumlu yönde etkilemektedir. Son olarak üçüncüsü, öğrencilerin özerk akademik motivasyonu okul başarısında doğrudan bir etkiye sahiptir. Yani akademik alanda yetersiz hisseden ya da okul bağlamında kontrollü hisseden hatta çoğu zaman 
istemediği şeyleri yapmak noktasında yönlendirilen çocuk, akademik motivasyon eksikliği yaşayabilir. $\mathrm{Bu}$ durum öğrencinin okul başarısında bir düşüşe sebep olur.

Algılanan akademik yeterlik, öğrencilerin akademik bir işi gerçekleştirmek için gerekli olan bilgi, beceri ve güce sahip olup olmamasıyla ilgili inancıdır. Akademik özerklik, öğrencilerin okulda özgür seçimler yapmalarına izin ve destek verilmesiyle ilgili algılarıdır. Modelde söz konusu duygunun yakın arkadaşlar ya da öğretmenler tarafından hissettirilip hissettirilmediğiyle ilgili öğrenci algıları, arkadaş ve öğretmen özerklik desteği değişkenini oluşturmaktadır.

Özerk akademik motivasyon ise öz belirleme durumunun ya da özerkliğin en çok yaşandığı motivasyona (içsel motivasyon gibi) vurgu yapar. Örneğin okula bir seçme duygusu yaşayarak giden ya da akademik etkinlikleri yaparken memnuniyet ve tatmin duygusu hisseden bir öğrencinin özerk motivasyon stiline sahip olduğu düşünülür. Tersi durumda okul etkinliklerini dışsal birtakım baskılardan ötürü gerçekleştiren ya da hiç motivasyona sahip olmayan öğrencilerin ise akademik alanda özerk olmayan bir motivasyon stiline sahip olduğu düşünülür.

Kat1lımc1lar

Araştırmaya Ankara il merkezi sınırlarındaki ilköğretim okulları arasından Etimesgut ilçe merkezi ve Eryaman semtinden seçilmiş 17 ilköğretim okulundaki ilköğretim beşinci sınıf öğrencileri katılmıştır. Ön uygulamaya katılan öğrencilerin 132'si erkek (\%29), 323'ü kızdır (\%71). Asıl uygulamaya ise 345 (\%41) erkek, 504 (\%59) kız, toplamda 849 öğrenci katılmıştır.

Test Edilecek Motivasyonel Modelde Yer Alan Değişkenler

Modelde (1) öğretmenle ilgili algılanan özerklik desteği, (2) arkadaşlarla ilgili algılanan özerklik desteği, (3) algılanan akademik yeterlik, (4) algılanan akademik özerklik (öz belirlenmişlik), (5) özerk akademik motivasyon (öz belirlenmiş akademik motivasyon) ve (6) akademik başarı (performans) değişkenleri yer almaktadır.

1. Algılanan öğretmen özerklik desteği: Bu değişken, sınıf öğretmenlerinin okuldaki özerkliği destekleyip desteklememesiyle ilgili öğreci algısına işaret etmektedir.

Sınıf öğretmenlerinin okuldaki özerkliği desteklemesiyle ilgili öğrenci algısını ölçmek için Pelletier, Beaudry, Sharp ve Otis (2008) tarafından geliştirilen "Interpersonal Behaviors Scale (IBS)" isimli ölçek, maddeler öğretmen davranışını sorgular mahiyette düzenlenerek uyarlanmıştır.

2. Algılanan arkadaş özerklik desteği: Bu değişken, özellikle yakın arkadaşların okuldaki özerkliği destekleyip desteklememesiyle ilgili öğreci algısına işaret etmektedir.

Yakın arkadaşların okuldaki özerkliği desteklemesiyle ilgili öğrenci algısını ölçmek için "Interpersonal Behaviors Scale (IBS)" isimli ölçek, maddeler yakın arkadaş davranışını sorgular mahiyette düzenlenerek kullanılmıştır (Pelletier, Beaudry, Sharp ve Otis, 2008).

3. Algılanan akademik yeterlik: Yeterlik, bireyin genel olarak yaşamla baş etmede, amaçlarını gerçekleştirmede, görevlerini yerine getirmede yeterli olduğu duygusunu yaşamasıdır. Kuram kapsamında yeterlik, aynı zamanda psikolojik bir ihtiyaç olarak görülmektedir.

$\mathrm{Bu}$ araştırmada test edilen modeldeki akademik yeterlik ise öğrencinin akademik alanda hissettiği etkililik algısı olarak tanımlanmaktadır. Bu algıyı ölçmek için Susan Harter tarafından geliştirilen "Self Perception For Profile" isimli ölçeğin Güçlü Şekercioğlu tarafindan yapılan "Çocuklar için Benlik Algısı Profili”" isimli uyarlama çalışması kullanılmıştır (Şekercioğlu, 2009).

4. Algılanan akademik özerklik (algılanan akademik öz belirleme): Özerklik ihtiyacı, bir kişinin içsel ya da dışsal bir baskı hissetmeden, bağımsız olarak bir deneyim yaşama beklentisidir. Özerklik, bireyin kendi etkinliklerini kendisinin yönetmesi, bir başka ifadeyle özgürce "seçme" duygusunu yaşamasıdır. 
Akademik özerklik ise öğrencinin okul görevleri ya da bizzat okulun kendisiyle ilgili hissettiği özerklik algısı olarak tanımlanmaktadır. Öğrencilerin akademik alandaki özerklik algısını ölçmek için "Perceived Autonomy In Life Domains Scale (PALDS-16)" isimli ölçeğin uyarlama çalışması kullanılmıştır (Blais, Vallerand, Lachance, 1990).

5. Özerk akademik motivasyon: Özerk akademik motivasyon, davranışsal düzenlemenin en özerk şekline atıfta bulunur. Daha önce de değinildiği gibi düzenlemenin en özerk şekli, seçme duygusunun en çok yaşandığı, kişiye memnuniyet ve tatmin duygusu yaşatan içsel motivasyondur.

$\mathrm{Bu}$ araştırmada kulanılan modeldeki bir değişken olarak özerk akademik motivasyon, öğrencilerin okulla ilgili işler konusundaki davranışlarının sebebini sorgular. Öğrenci, söz konusu davranışı hoşnutluk içinde zevk alarak mı yapmaktadır, ailesi ya da öğretmenleri istiyor diye mi, yoksa tam olarak içselleştiremese de kendi istediği için mi? Belki de öğrenci, söz konusu davranışı tam bir güdüsüzlük hali ile yönetmektedir. Yani özerk akademik motivasyon, öğrencilerin okulla ilgili çeşitli konularda yaptıkları şeyi niçin yaptıklarını belirlemeye odaklanmıştır.

Öğrencilerin özerk akademik motivasyonunu ölçmek için Vallerand ve diğerlerinin (http://www.er.uqam.ca/nobel/r26710/LRCS/echelles_en.htm) geliştirdiği "Academic Motivation Scale (AMS-Elementary)" isimli ölçeğin uyarlama çalışması kullanılmıştır.

6. Akademik başarı: Akademik başarı, çoğunlukla bilişsel beceri ve yeterliğe işaret etmekte ve derslerde gösterilen performansın betimlenmesine dayanmaktadır. Akademik başarı ya da bir başka ifadeyle okul başarısı, öğrencinin bulunduğu okul, sınıf ve derse göre belirlenmiş hedeflere ulaşmada göstermiş olduğu ilerlemedir.

Bu çalışmada "akademik başarı" gizil değişkeninin belirleyicisi olarak, öğrencilerin dönemlik not ortalamaları kullanılmıştır.

\section{Bulgular}

$\mathrm{Bu}$ bölümde araştırmanın amaçları doğrultusunda oluşturulan soruların cevaplarına ilişkin bulgular paylaşılmıştır. Kuramsal model, path analizi yoluyla sınanmıştır. Öncelikle verilerin kovaryans matrisi verilmiş (Tablo 1), ardından modelin standart diyagramına ait standardize edilmiş sonuçlar (Tablo 2) paylaşılmıştır. 
Tablo 1.

Gizil ve Gözlenen Değişkenlere Ait Kovaryans Matrisi

basari3 basari2 basaril indeks4 indeks3 indeks2 indeks1 yaö2 yaö6 yaö11 yaö15 çibap6 çibap5 çibap4 çibap3 çibap2 çibap1 aibs3 aibs5 aibs10 ibs3 ibs5 ibs10

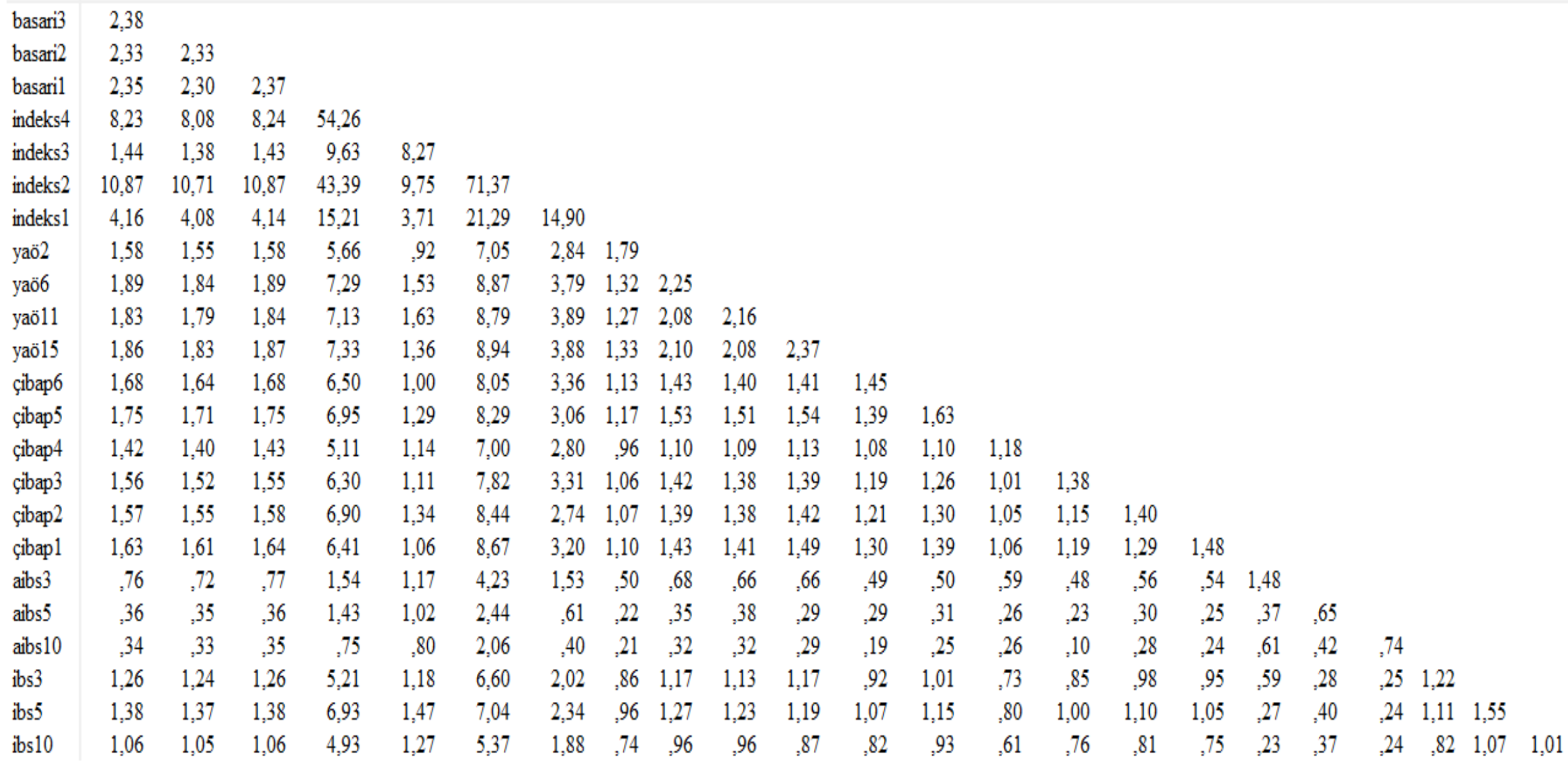


Modelde yer alan değişkenlerin karşılaştırılabilmesi için Tablo 2'de, ortak bir referans sağlaması açısından parametrelerin standardize edilmiş sonuçları verilmiştir.

Tablo 2.

Modele Ait Standardize Edilmiş Sonuçlar

\begin{tabular}{|c|c|c|c|}
\hline & & & $\begin{array}{l}\text { Regresyon } \\
\text { ağırlığı }\end{array}$ \\
\hline yeterlikalgisi & $<---$ & ozerklikdestek1 &, 80 \\
\hline ozerklikalgisi & $<---$ & ozerklikdestek1 & .72 \\
\hline yeterlikalgisi & $<--$ & ozerklikdestek2 &, 04 \\
\hline ozerklikalgisi & $<---$ & ozerklikdestek2 &, 09 \\
\hline ozrkmotivasyon & $<--$ & ozerklikdestek1 &, 10 \\
\hline ozrkmotivasyon & $<--$ & ozerklikdestek2 &, 04 \\
\hline ozrkmotivasyon & $<--$ & yeterlikalgisi & 91 \\
\hline ozrkmotivasyon & $<--$ & ozerklikalgisi &, 14 \\
\hline basari & $<--$ & ozrkmotivasyon &, 81 \\
\hline ibs 10 & $<---$ & ozerklikdestek1 &, 89 \\
\hline ibs 5 & $<---$ & ozerklikdestek1 & 94 \\
\hline ibs3 & $<---$ & ozerklikdestek1 &, 86 \\
\hline aibs10 & $<---$ & ozerklikdestek2 &, 86 \\
\hline aibs5 & $<---$ & ozerklikdestek2 & .69 \\
\hline aibs3 & $<---$ & ozerklikdestek2 &, 65 \\
\hline çibap1 & $<---$ & yeterlikalgisi & 94 \\
\hline çibap2 & $<---$ & yeterlikalgisi & ,93 \\
\hline çibap3 & $<---$ & yeterlikalgisi & 91 \\
\hline çibap4 & $<---$ & yeterlikalgisi &, 87 \\
\hline çibap5 & $<---$ & yeterlikalgisi & 94 \\
\hline çibap6 & $<---$ & yeterlikalgisi & 94 \\
\hline yaö15 & $<---$ & ozerklikalgisi & 94 \\
\hline yaö11 & $<---$ & ozerklikalgisi & 98 \\
\hline yaö6 & $<---$ & ozerklikalgisi & 97 \\
\hline уаӧ2 & $<---$ & ozerklikalgisi &, 68 \\
\hline indeks1 & $<---$ & ozrkmotivasyon &, 72 \\
\hline indeks2 & $<---$ & ozrkmotivasyon &, 87 \\
\hline indeks3 & $<---$ & ozrkmotivasyon &, 40 \\
\hline indeks4 & $<---$ & ozrkmotivasyon &, 79 \\
\hline basaril & $<---$ & basari & 99 \\
\hline basari2 & $<---$ & basari & 99 \\
\hline basari3 & $<---$ & basari & 1,00 \\
\hline
\end{tabular}

Tablo 2 incelendiğinde özerklik destek1 olarak adlandırılan öğretmen özerklik destekleyiciliğiyle ilgili ölçek puanı 1 standart sapma değeri arttığında yeterlik algısının .80 , özerklik algısının .72 düzeyinde arttığı görülmektedir. Benzer şekilde özerklik destek2 olarak adlandırılan arkadaş özerklik destekleyiciliğiyle ilgili ölçek puanı 1 sapma arttığında yeterlik algısının .04, özerklik algısının .09 düzeyinde arttığı görülmektedir. Tabloya göre özerklik destek1 değişkeninin özerk motivasyon üzerindeki etkisi 10 iken özerklik destek2 değişkeninin özerk motivasyon üzerindeki etkisi .04'tür ve bu ilişki anlamsız çıkmıştır. 
Tablo 2'den anlaşılacağı üzere yeterlik algısı puanları, 1 sapma arttığında özerk motivasyonda .91'lik bir artış olmaktadır. Ancak özerklik algısının özerk motivasyona etkisi, .14 birim kadardır. Son olarak özerk motivasyon 1 sapma değerinde arttı̆̆ında akademik başarı .81 oranında artmaktadır.

Tablo 3 ve Tablo 4 'te modelde yer alan değişkenlerin birbirine doğrudan ve toplam etkileri verilmiştir.

Tablo 3

Değişkenlerin Birbirine Doğrudan Etkileri

\begin{tabular}{|c|c|c|c|c|c|c|}
\hline & ozerklikdestek1 & ozerklikdestek2 & ozerklikalgisi & yeterlikalgisi & ozrkmotivasyon & basari \\
\hline ozerklikalgisi &, 72 &, 09 &, 00 &, 00 &, 00 &, 00 \\
\hline yeterlikalgisi & 80 &, 04 &, 00 & .00 & .00 & ( \\
\hline ozrkmotivasyon &, 10 & 04 &, 14 & 91 &, 00 & , \\
\hline basari & 00 & .00 & 00 & .00 & 81 & .0 \\
\hline basari3 &, 00 & .00 &, 00 & .00 &, 00 & 1,0 \\
\hline basari2 &, 00 &, 00 &, 00 &, 00 &, 00 & 95 \\
\hline basaril &, 00 &, 00 &, 00 &, 00 &, 00 & 95 \\
\hline indeks4 &, 00 &, 00 &, 00 &, 00 &, 79 & 00 \\
\hline indeks3 & .00 &, 00 &, 00 &, 00 & 40 & 0 \\
\hline indeks2 &, 00 & .00 &, 00 &, 00 & 87 & 00 \\
\hline indeks1 & .00 & .00 & 00 & .00 &, 72 & 00 \\
\hline уаӧ2 & 00 & .00 & 68 & .00 & 00 &, 00 \\
\hline yаö6 & 00 & .00 & 97 & 00 & 00 &, 00 \\
\hline yaö11 & 00 & .00 &, 98 & 00 & 00 &, 00 \\
\hline yaö15 &, 00 &, 00 & 94 & .00 &, 00 & $=0$ \\
\hline çibap6 &, 00 &, 00 &, 00 & 94 &, 00 & \\
\hline çibap5 & .00 & .00 & .00 & 94 & .00 & \\
\hline çibap4 &, 00 &, 00 &, 00 & 87 &, 00 & \\
\hline çibap3 &, 00 &, 00 &, 00 & 91 &, 00 & \\
\hline çibap2 &, 00 & .00 &, 00 & ,93 &, 00 & $=($ \\
\hline çibap1 & .00 & .00 & .00 & 94 & 00 & \\
\hline aibs3 &, 00 & 65 & .00 & .00 & 00 & : \\
\hline aibs5 &, 00 & 69 &, 00 & .00 &, 00 &, 0 \\
\hline aibs 10 &, 00 & 86 &, 00 &, 00 &, 00 &, 0 \\
\hline ibs3 &, 86 & .00 &, 00 & .00 &, 00 &, 0 \\
\hline ibs5 & 94 & .00 & .00 & .00 & .00 & \\
\hline ibs 10 & 89 &, 00 &, 00 &, 00 &, 00 & \\
\hline
\end{tabular}

Tablo 3 incelendiğinde özerklik destek1 değişkeninin özerklik algısına, yeterlik algısına ve özerk motivasyona doğrudan etkisi olduğu görülmektedir $(.72, .80, .10)$. Benzer şekilde özerklik destek2 değişkeninin özerklik algısına, yeterlik algısına ve özerk motivasyona doğrudan etkisi olduğu görülmektedir $(.09, .04, .04)$. Tablo 8'e göre özerklik algısı ve yeterlik algısı değişkenlerinin özerk motivasyona $(.14, .91)$; özerk motivasyonun da başarıya doğrudan etkisi söz konusudur (.81). 
Tablo 4.

Değişkenlerin Birbirine Toplam Etkileri

\begin{tabular}{l|rrrrrr} 
& ozerklikdestek1 & ozerklikdestek2 & ozerklikalgisi & yeterlikalgisi & ozrkmotivasyon & basari \\
\hline ozerklikalgisi &, 72 &, 09 &, 00 &, 00 &, 00 &, 00 \\
yeterlikalgisi &, 80 &, 04 &, 00 &, 00 &, 00 &, 00 \\
ozrkmotivasyon &, 81 &, 09 &, 14 &, 91 &, 00 &, 00 \\
basari &, 77 &, 08 &, 00 &, 86 &, 81 &, 00 \\
basari3 &, 77 &, 08 &, 00 &, 86 &, 95 & 1,00 \\
basari2 &, 76 &, 08 &, 00 &, 86 &, 94 &, 99 \\
basari1 &, 76 &, 08 &, 00 &, 86 &, 94 &, 99 \\
indeks4 &, 64 &, 07 &, 00 &, 72 &, 79 &, 00 \\
indeks3 &, 32 &, 03 &, 00 &, 36 &, 40 &, 00 \\
indeks2 &, 71 &, 07 &, 00 &, 80 &, 87 &, 00 \\
indeks1 &, 59 &, 06 &, 00 &, 66 &, 72 &, 00 \\
yaö2 &, 49 &, 06 &, 68 &, 00 &, 00 &, 00 \\
yaö6 &, 70 &, 09 &, 97 &, 00 &, 00 &, 00 \\
yaö11 &, 70 &, 09 &, 98 &, 00 &, 00 &, 00 \\
yaö15 &, 68 &, 08 &, 94 &, 00 &, 00 &, 00 \\
çibap6 &, 75 &, 04 &, 00 &, 94 &, 00 &, 00 \\
çibap5 &, 75 &, 04 &, 00 &, 94 &, 00 &, 00 \\
çibap4 &, 04 &, 00 &, 87 &, 00 &, 00 \\
çibap3 &, 69 &, 04 &, 00 &, 91 &, 00 &, 00 \\
çibap2 &, 72 &, 04 &, 00 &, 93 &, 00 &, 00 \\
çibap1 &, 74 &, 04 &, 00 &, 94 &, 00 &, 00 \\
aibs3 &, 75 &, 04 &, 00 &, 00 &, 00 \\
aibs5 &, 00 &, 65 &, 00 &, 00 &, 00 &, 00 \\
aibs10 &, 00 &, 69 &, 00 &, 00 &, 00 &, 00 \\
ibs3 &, 00 &, 86 &, 00 &, 00 &, 00 &, 00 \\
ibs5 &, 86 &, 00 &, 00 &, 00 &, 00 &, 00 \\
ibs10 &, 94 &, 00 &, 00 &, 00 &, 00 &, 00 \\
&, 89 &, 00 &, 00 &, 00 &, 00 &, 00
\end{tabular}

Sonuçlar ilköğretim 5. Sınıf öğrencilerinin okulla ilgili konularda öğretmenlerinden aldığı özerklik desteğinin onların akademik yeterliklerini doğrudan etkilediğini ancak yakın arkadaşlarından aldığı özerklik desteğinin akademik yeterliliği etkilemediğini göstermektedir.

İlköğretim 5. Sınıf öğrencilerinin okulla ilgili konularda öğretmenlerinden aldığı özerklik desteği onların akademik özerkliklerini de doğrudan etkilemektedir. İlköğretim 5. Sınıf öğrencilerinin okulla ilgili konularda yakın arkadaşlarından aldığı özerklik desteğinin onların akademik özerkliklerine doğrudan fakat zayıf etkisi söz konusudur.

İlköğretim 5. Sınıf öğrencilerinin okulla ilgili konularda öğretmenlerinden aldığı özerklik desteği onların özerk akademik motivasyonlarını doğrudan etkilemektedir. İlköğretim 5. Sınıf öğrencilerinin okulla ilgili konularda yakın arkadaşlarından aldığı özerklik desteği onların özerk akademik motivasyonlarını doğrudan etkilemektedir.

İlköğretim 5. Sınıf öğrencilerinin kendileriyle ilgili algıladıkları akademik yeterlik, özerk (öz belirlenmiş) akademik motivasyonlarını kuvvetli ve doğrudan etkilemektedir. Ancak öğrencilerin kendileriyle ilgili algıladıkları akademik özerkliğin onların özerk (öz belirlenmiş) akademik motivasyonlarına etkisi doğrudan olmakla beraber düşüktür. Son olarak ilköğretim 5. Sınıf öğrencilerinin özerk (öz belirlenmiş) akademik motivasyonları, onların okul performansını (akademik başarı) doğrudan ve kuvvetli etkilemektedir. 


\section{Modelin Uyum İndeksleri}

Araştırmada nihai modele ilişkin elde edilen uyum katsayıları kabul edilen sınırlarda çıkmıştır. NFI, CFI, GFI ve AGFI'nın .90'ın üzerinde çıkması o modelin iyi uyum gösterdiğine işaret etmektedir (SchermellehEngel ve Moosbrugger, 2003; Sümer, 2000). Analiz sonucunda kuramsal modelin ki kare $\left(\aleph^{2}=1795.8 p<.01\right)$ iyilik uyum indeksi yüksek ve manidar çıkmıştır. Bu değerin yüksek ve manidar çıkması modelin uyum göstermediği şeklinde yorumlanmasına rağmen (Hoyle, 1995; Sümer, 2000) büyük örneklemlerde tek başına çok fazla anlam ifade etmemektedir (Tabachnick ve Fidel, 2007). Bu nedenle daha iyi bir ölçüt olan ki kare değerinin serbestlik derecesine oranına $\left(\mathrm{\kappa}^{2} / \mathrm{sd}\right)$ bakılmıştır. Bu oranın kabul edilebilir değeri $\mathrm{\kappa}^{2} / \mathrm{sd} \leq 5$ olmalıdır (Kline, 2005). Yapılan analize bakıldığında ise bu değerin belirtilen kesme noktasından daha yüksek olduğu $\left(\aleph^{2} / s d=1795.8 / 290=6.19\right)$ görülmektedir.

Fakat, path modeline ait RMSEA, RMR değerlerinin 0.01'den küçük olmasının kabul edilebilir olduğu ve örneklem sayısı yüksek gruplarda ki kare değerinin yüksek çıkmasının muhtemel olduğu belirtilmektedir (Şimşek, 2007). Araştırmada modelin bazı indeksler (AGFI, CFI, GFI, NFI) için "iyi" bazı indeksler (RMSA, RMR) için "kabul edilebilir" uyum gösterdiğini söylemek mümkündür.

Analizde uyum indekslerinden biri olan RMSEA incelendiğinde yüksek olarak kabul edilen 0.083 değeri elde edilmiştir. RMSEA'nın .05'ten küçük olması mükemmel ve 0.08 'den düşük olması iyi uyuma işaret ederken (Joreskob ve Sorbom, 1993), 0.10'dan düşük olması zayıf uyuma işaret etmektedir. Bu durumda elde edilen uyum indeksi $($ RMSA $=0.083)$, verilerle model arasında kabul edilir bir uyum olduğunu göstermektedir.

Tablo 5'teki AGFI, GFI, NFI uyum indeksleri incelendiğinde elde edilen değerler kabul edilebilir düzeydedir.

Tablo 5 .

Nihai Modelin Uyum Katsaylları

\begin{tabular}{ll}
\hline Ki-Kare/Serbestlik Derecesi $\left(\chi^{2} / \mathrm{sd}\right)$ & 6.19 \\
\hline Kestirim Hatası Kareler Ortalamasının Karekökü (RMSEA) & .0083 \\
\hline Normlaştırılmış Uyum indeksi (NFI) & .909 \\
\hline Hata Kareler Ortalaması Karekökü (RMR) & .059 \\
\hline Karşılaştırmalı Uyum indeksi (CFI) & .889 \\
\hline Uyum İyiliği indeksi (GFI) & .917 \\
\hline Düzeltilmiş Uyum iyiliği indeksi (AGFI) & .923 \\
\hline
\end{tabular}

$\mathrm{Bu}$ istatistikler doğrultusunda oluşan modelin standart diyagramı aşağıdaki gibidir. 


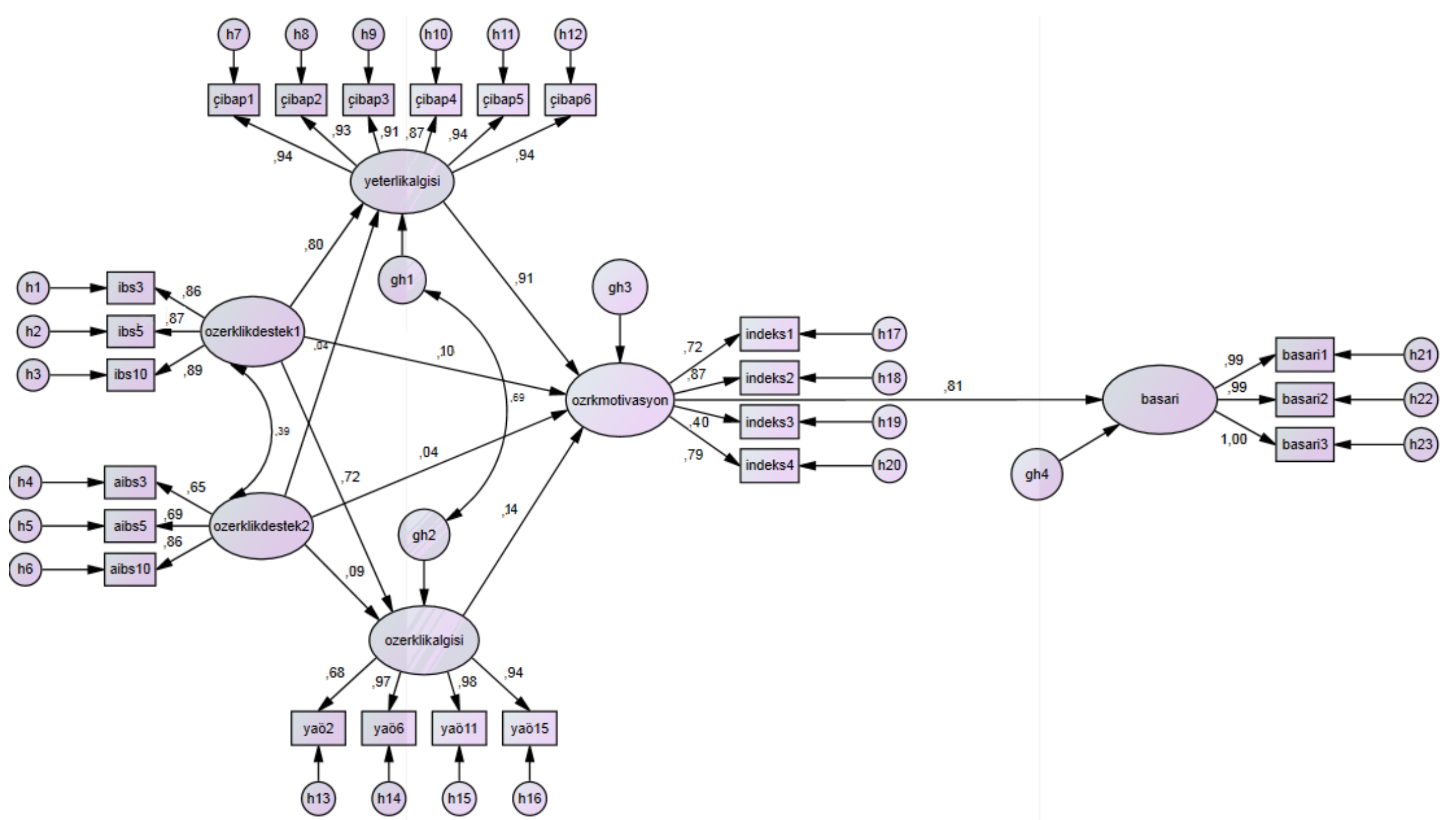

Şekil 2. Oluşan Modelin Standart Diyagramı 


\section{Sonuç}

1. Sonuçlar ilköğretim 5. Sınıf öğrencilerinin okulla ilgili konularda öğretmenlerinden aldığı özerklik desteğinin onların akademik yeterliklerini doğrudan etkilediği, yakın arkadaşlarından aldığı özerklik desteğinin ise akademik yeterliliği etkilemediğini göstermektedir.

2. İlköğretim 5. Sınıf öğrencilerinin okulla ilgili konularda öğretmenlerinden aldığı özerklik desteği onların akademik özerkliklerini doğrudan etkilemektedir.

3. İlköğretim 5. Sınıf öğrencilerinin okulla ilgili konularda yakın arkadaşlarından aldığı özerklik desteğinin onların akademik özerkliklerine doğrudan fakat zayıf etkisi söz konusudur.

4. İlköğretim 5. Sınıf öğrencilerinin okulla ilgili konularda öğretmenlerinden aldığı özerklik desteği onların özerk akademik motivasyonlarını doğrudan etkilemektedir. İlköğretim 5. Sınıf öğrencilerinin okulla ilgili konularda yakın arkadaşlarından aldığı özerklik desteği onların özerk akademik motivasyonlarını doğrudan etkilemektedir.

5. İlköğretim 5. Sınıf öğrencilerinin kendileriyle ilgili algıladıkları akademik yeterlik, özerk (öz belirlenmiş) akademik motivasyonlarını kuvvetli ve doğrudan etkilemektedir. Ancak öğrencilerinin kendileriyle ilgili algıladıkları akademik özerkliğin onların özerk (öz belirlenmiş) akademik motivasyonlarına etkisi doğrudan olmakla beraber düşüktür. Son olarak ilköğretim 5. Sınıf öğrencilerinin özerk (öz belirlenmiş) akademik motivasyonları, onların okul performansını (akademik başarı) doğrudan etkilemektedir.

6. Ayrıca test edilen modele ilişkin uyum indeksleri incelendiğinde modeldeki veriler modele uyum sağlamıştır ve modelin bu şekliyle kabul edilebilir olduğu görülmüştür.

\section{Öneriler}

1. Bireylerin seçim duygusunu yaşamaları onların içinde bulundukları ortamın özerklik destekleyici olmasına bağlıdır. Bu bağlamda düşünüldüğünde bireyler, çevreden özerklik desteği aldıklarında özbelirleme düzeyleri yükselmektedir. Çünkü bireyler davranışlarını isteyerek ve gönüllü olarak seçtiklerinde, kontrol edilmediklerinde, bask1 ve zorlama hissetmediklerinde öz-belirleme gerçekleşmektedir. Kontrol altında olan öğrenciler sadece heveslerini kaybetmez aynı zamanda yaratıcılık gerektiren, karmaşık, birçok kavramı bilmeyi gerektiren konularda öğrenme güçlüğü de yaşayabilirler.

Özerk kişiler, öz-yeterlik algısı yüksek, uyum sağlayıcı ve çoğunlukla içsel olarak güdülenmiş bireylerdir. Özgür seçimler yapabilen, kendi kararlarını kendi veren, kendi davranışlarını dışsal bir kontrol olmadan düzenleyebilen ve onların sorumluluğunu üstlenen bireyler yetiştirmek için öğretmenlerin sınıfta öğrencilerin özerkliğini destekleme yanında onların yeterlik ve aidiyet duygusunu doyuracak bir atmosfer oluşturması yerinde olur.

2. Öğrencinin özerkliğini artırmada, öğretmenin en önemli rolü, bilgiye nasıl ulaşılır ve bilgi nasıl öğrenilir sorularının yanıtları için kaynak kişi ya da başka bir deyişle rehber olmaktır. Öğretmen öğrencinin kendi öğrenme süreci konusunda farkındalığını sağlamalı ve programların izin verdiği ölçüde hedef belirleme, içerik ve materyal seçimi, yöntem belirleme ve performans değerlendirmede söz sahibi olmasına izin vermelidir.

İnsanların kendileri için ve kendi tercihleriyle belirledikleri hedefler, sağlıklı hedeflerdir. Ancak başkaları tarafından belirlenen hedefler, kimi zaman tehlikeli yan etkiler yaratabilir. Bu yüzden öğretmenler öğrencileri sürekli kontrol etmek yerine onlardaki özerklik duygusunu canlandırmak ve onların kendi kendilerini yönetme becerisini elde etmesi için çaba sarf etmelidir. 
3. Çocukların kendi otoriteleri olmalı ve onlara istedikleri zaman istedikleri şeyi dayatma olmaksızın öğrenme özgürlüğü verilmelidir. Bu yolda öğretmen destekleyici rolü ihmal edilmemelidir. Özerklik öğretilebilen veya öğrenilebilen bir şey değildir; ancak kullanılan yöntemler, öğrenme malzemeleri, değerlendirme yöntemleri ve programların geliştirilmesinde dikkate alınacak bazı noktalar ile güçlendirilmesi mümkündür.

4. Çalışma sonucundan öğrencilerin yeterlik ve başarılarıyla ilgili öğretmen beklentilerinin, öğrenci başarısında önemli bir etken olduğu anlaşılmaktadır. Öğretmenler ve öğretmen adaylarına, öğrenciler başarabilecekleri ve yeterli olduklarına dair olumlu düşünceler beslediklerinde ve bu kendilerine ifade edildiğinde öğrencilerin içsel motivasyon, yeterlik algısı ve başarılarının bu durumdan olumlu etkilendiği çeşitli vesilelerle anlatılmalıdır.

5. Arkadaşların birbirlerinin akademik özerkliğini desteklemesi konusu ülkemizde üzerinde çok fazla durulan bir konu değildir. Bu çalışmada arkadaş özerklik destekleyiciliğin, yeterlik algısı ve özerklik algısına dolayısıyla akademik başarıya etkisi düşük seviyede çıkmış olsa da konunun yurt dışında yapılan çalışmalardaki önemi dikkate alınarak yapılacak bilimsel araştırmalarda arkadaş özerklik destekleyici yaklaşımlar üzerinde durulmalıdır.

\section{Kaynaklar}

Amabile, T. M. (1982). Children's artistic creativity detrimental effects of competition in a field setting. Personality and Social Psychology Bulletin, (8): 573-578.

Andersen, S. (2000). Fundamental human needs: making social cognition relevant. Psychological Inquiry, 11(4): 269-276.

Blais M. R., Vallerand R. J., Lachance L. (1990). Échelle de perception d'autodétermination dans les domaines de vie (ÉPADV-16). Development and Validation of the Autonomy Perceptions in Life Contexts Scale. Unpublished manuscript. University of Quebec at Montreal.

Cihangir-Çankaya, Z. (2005). Öz belirleme modeli: özerklik desteği, ihtiyaç doyumu ve iyi olma. (Yayınlanmamış Doktora Tezi), Gazi Üniversitesi, Eğitim Bilimleri Enstitüsü, Ankara.

Deci, E. L. \& Ryan R. M. (1980). Self-determination theory: When mind mediates behavior. Journal of Mind and Behavior. 1: 33-43.

Deci, E. L. \& Ryan R. M. (1985). Intrinsic Motivation and Self-Determination in Human Behavior. New York: Plenum Press.

Deci, E. L. \& Ryan, R. M. (2008). Facilitating optimal motivation and psychological well-being across life's domains. Canadian Psychology, 49: 14-23.

Graham, S. \& Golan, S. (1991). Motivational Influences on Cognition: Task İnvolvement, Ego Involvement and Depth of İnformation Processing. Journal of Educational Psychology, 83(2): 187-196.

Grolnick, W. S. \& Ryan, R. M. (1987). Autonomy in children's learning: An experimental and individual difference investigation. Journal of Personality and Social Psychology, (52): 890-898.

Grolnick, W. S., Deci, E. L. \& Ryan, R. M. (1997). Internalization within the family: The selfdetermination theory perspective. In J. E. Grusec \& L. Kuczynski (Eds.). Parenting and Children's Internalization of Values: A Handbook of Contemporary Theory (pp. 135-161). New York: Wiley. 
Guay, F., Boggiano, A. K. \& Vallerand, R. J. (2001). Autonomy support, motivation and perceived competence: Conceptual and empirical linkages. Personality and Social Bulletin, 27: 643650 .

Hoyle, R. H. (1995). Structural Equation Modeling: Concepts, Issues and Applications. London: Sage Publication Inc.

Joreskob, K. G. \& Sorbom, D. (1993). LISRESL 8: Structural equation modeling with the simpl/s command language, Ssi Scientific Software.

Kline, R. B. (2005). Principles and Practices of Structural Equation Modeling. New York: Guilford Press

Kowal, J., \& Fortier, M. S. (1999). Motivational determinants of flow: Contributions from selfdetermination theory, Journal of Social Psychology, 139, 355-368.

Nolen, S. B. \& Haladyna, T. M. (1990). Motivation and Studying in High School Science. Journal of Research on Science Teaching, 27: 115-126.

Ormrod, J. E. (1999). Human Learning. Upper Saddle River, NJ: Prentice-Hall.

Pelletier, L. G., Beaudry, S., Sharp, E. \& Otis, N. (2008). The interpersonal behaviors scale: a measure of autonomy support, competence and relatedness in different life domains. Manuscript in preparation, University of Ottawa, Ontario, Canada.

Pintrich, P., R. \& De Groot, E. V. (1990). Motivational and Self-Regulated Learning Compenents of Classroom Academic Performance. Journal of Educational Psychology, 82(1): 33-40.

Ryan, R. M. and Deci, E. L. (2000a). Intrinsic and extrinsic motivations: Classic definitions and new directions. Contemporary Educational Psychology, 25: 54-67.

Schermelleh-Engel, K. \& Moosbrugger, H. (2003). Evaluating the fit of structural equation models: tests of significance and descriptive goodness-of-fit measures. Methods of Psychological Research Online, 8(2): 23-74.

Sümer, N. (2000). Yapısal eşitlik modelleri: temel kavramlar ve örnek uygulamalar. Türk Psikoloji Yazllarl, 3(6): 49-74

Şekercioğlu, G. (2009). Çocuklar İçin Benlik Algısı Profilinin Uyarlanması ve Faktör Yapısının Farklı Değişkenlere Göre Eşitliğinin Test Edilmesi (Yayınlanmamış Doktora Tezi) Ankara Üniversitesi, Ankara.

Şimşek, Ö. F. (2007). Yapısal Eşitlik Modellemesine Giriş. Ankara: Ekinoks

Tabachnick, B. G. \& Fidel, L. S. (2007). Using Multivariate Statistics (5th edition). Boston: Allyn and Bacon

Vallerand, R. J. \& Bissonnette, R. (1992). On the Predictive Effect of Intrinsic, Extrinsic and Amotivational Styles on Behavior: A Prospective Study. Journal of Personality, 60: 599620 .

Vallerand, R. J., Fortier, M. S. \& Guay, F. (1997). Self-determination and persistence in a real-life setting: Toward a motivational model of high school dropout. Journal of Personality and Social Psychology, 72(5): 1161-1176. 
Véronneau, M. H., Koestner, R. F. \& Abela, J. R. Z. (2005). Intrinsic need satisfaction and well-being in children and adolescents: An application of the self determination theory. Journal of Social and Clinical Psychology, 24(2): 280-292.

Wong, Eugene H.; Wiest, Dudley J. \& Cusick, Lisa B. (2002). Perceptions of autonomy support, parent attachment, competence and self-worth as predictors of motivational orientation and academic achievement: An examination of sixth-and-ninth-grade regular education students. Adolescence, 37(146): 255-266.

Wößmann L., Schütz, G., Lüdemann, E. \& West M. R. (2007). School Accountability, Autonomy, Choice and the Equity of Student Achievement: International Evidence from PISA 2003. OECD Education Working Paper No.12, EDU/WKP(2007)7. Paris: OECD. http://www.elternlobby.ch/deutsch/argumente/pdf/fbw13woessmann.pdf adresinden 11.01.2013 tarihinde erişilmiştir.

Wößmann, L. (2007). International Evidence on School Competition, Autonomy and Accountability: A Review. Peabody Journal of Education, 82 (2-3): 473-497.

http://www.er.uqam.ca/nobel/r26710/LRCS/echelles_en.htm.

\section{Extended Abstract}

Purpose

Self determination theory makes specific predictions concerning motivational consequences. According to this theory, autonomous forms of motivation (intrinsic motivation) lead to positive outcomes, whereas less autonomous types (amotivation) bring out negative consequences. Many studies examining the relationship between motivation and outcome variables have been conducted in the educational domain.

This study focused on the impact of various variables based on self determination theory such as the "perceived competence", "autonomy" and "autonomy support" to autonomous academic motivation and academic achievement. In this study the effect of teachers and close friends's autonomy support perceived by primary fifth grade students' to academic competence, academic autonomy and autonomous academic motivation, and the effect of autonomous academic motivation to academic success are researched. The main aim of the study is to test the self-determination theory-based structural motivational model on academic success.

The following hypotheses were tested in accordance with the general aim of the study:

1. Fifth grade students' autonomy support get by teachers directly influence their competence.

2. Fifth grade students' autonomy support get by close friends directly influence their competence.

3. Fifth grade students' autonomy support get by teachers directly influence their academic autonomy.

4. Fifth grade students' autonomy support get by close friends directly influence their academic autonomy.

5. Fifth grade students' autonomy support get by teachers directly influence their autonomous academic motivation.

6. Fifth grade students' autonomy support get by close friends directly influence their autonomous academic motivation. 
7. Fifth grade students' academic competence they perceived related themselves influences their autonomous (self-determined) academic motivation directly.

8. Fifth grade students' academic autonomy they perceived related themselves influences their autonomous (self-determined) academic motivation directly.

9. Fifth grade students' autonomous (self-determined) academic motivations influences directly their school performance (academic achievement)

10. The model is acceptable.

The study is a descriptive study in survey model, quantitative data was collected in this study. The study group consists of 849 fifth grade students in selected from 17 primary schools in Eryaman and Etimesgut in Ankara. The collection of data was conducted in four stages. In first stage, data were translated from English to Turkish and expert assesment was provided. The second stage, the first pilot trial was conducted with open-ended questions and pilot scale items. The second pilot trial in which statistical analyzes were performed was carried out in the third stage. In the fourth and final stage, main study was conducted using final version of scale items. "Perceived Autonomy In Life Domains Scale", "Interpersonal Behavior Scale (to inquire about teacher behavior)", "Interpersonal Behavior Scale (to inquire about the behavior of a close friend)", "Academic Motivation Scale (Elementary Level)" and "Self-Perception Profile for Children" are used to measure the variables in the tested model within the scope of research. Responses to scale items used in order to collect quantitative data were analyzed by structural equation modeling.

\section{Results and Discussion}

Curiosity is a fundamental tendency for human beings. Discovery, learning, understanding, or the desire to know exist in human nature and these are potentially main motivator of educational process. In educational literature, many studies have been conducted regarding motivation and the relationship between motivation and some factors such as academic achievement, well-being, creativity. Self determination theory, theoretical source to important part of these works, has had an important place in education literature with an intense focus on the three basic psychological needs and intrinsic motivation.

It is alleged that the three psychological needs accepted universally are emphasized in Self determination theory. Autonomy, one of these needs, is that person feels himself/herself in the center of his/her actions. Another psychological need theory mentioned, competence, is defined as the capacity to adapt to the environment effectively and to interact with the environment. The third need, relatedness, is that a person desires to be connected with others and to live feeling sense of "belonging" corresponding in the social environment.

When the scale score for teacher autonomy supportive increase 1 standard deviation, the scale score for competence increase .80 , and autonomy score increase .72 level. Similarly when the scale score for close friend autonomy supportive increase 1 standard deviation, the scale score for competence increase .04, and autonomy score increase .09 level. When the scale score for competence increase 1 standard deviation, the scale score for autonomy motivation increase .91 level. However, the perception of autonomy has an effect of 14 units for autonomous motivation. When the scale score for autonomous motivation increase 1 standard deviation, the score for academic achievement increase .81 level.

According to the results of the quantitative measurements that fifth grade students' autonomy support get by teachers directly influence the perceived competence, but the results of the quantitative measurements that autonomy support get by close friends didn't influence academic competence. 
Students' autonomy support get by teachers on the issues related school directly influence their academic autonomy. Students' autonomy support get by close friends on the issues related school directly influence their academic autonomy but this effect is low. Students' autonomy support get by teachers and close friends on the issues related school directly influence their autonomous academic motivation. Students' academic competence they perceived related themselves influences their autonomous (self-determined) academic motivation directly and strongly. However, students' academic autonomous they perceived related themselves influences their autonomous (selfdetermined) academic motivation directly but lowly. Finally, students' autonomous (self-determined) academic motivations influences directly their school performance (academic achievement). According to RMSEA, AGFI, RMR, GFI, NFI fit indices, widely used in the literature, it is likely to say that the model is acceptable.

Conclusion

We can talk about the existence of intrinsic motivation as long as the child's natural curiosity and interest exist in learning. It is likely to improve this motivational learning source, in case of the provision of favorable opportunities through educational environment, resources enriched by stimuli and autonomy. In accordance with research results, to be able to raise children who can choose freely, take their own decisions, regulate their own behavior without external control, claim responsibility, it is recommended to parents and teachers to create an atmosphere where their autonomy and their competence are supported and a sense of belonging (relatedness) is created.

Keywords: Self determination, autonomy, autonomy support, competence, autonomous academic motivation, academic achievement 